\title{
Simultaneous vertebral and subclavian artery stenting
}

\author{
Damian R. Maciejewski ${ }^{1}$, Łukasz Tekieli ${ }^{1}$, Roman Machnik ${ }^{2}$, Anna Kabłak-Ziembicka ${ }^{1}$, Tadeusz Przewłocki ${ }^{1,2}$, \\ Piotr Paluszek², Mariusz Trystuła², Robert Musiał’ ${ }^{3}$ Karolina Dzierwa ${ }^{1}$, Piotr Pieniążek ${ }^{1,2}$ \\ ${ }^{1}$ Department of Interventional Cardiology, Institute of Cardiology, Jagiellonian University Medical College, John Paul II Hospital, Krakow, Poland \\ 2Department of Vascular Surgery and Endovascular Interventions, John Paul II Hospital, Krakow, Poland \\ ${ }^{3}$ Department of Anesthesiology and Intensive Care, John Paul II Hospital, Krakow, Poland
}

Adv Interv Cardiol 2017; 13, 2 (48): 142-149

DOI: https://doi.org/10.5114/pwki.2017.68052

\begin{abstract}
A bstract
Introduction: Vertebrobasilar territory ischemia leads to disabling neurological symptoms and may be caused both by vertebral artery (VA) and subclavian artery (SA) stenosis. The coexisting symptomatic ipsilateral VA and proximal SA stenosis should be considered as a true bifurcation lesion for percutaneous treatment.

Aim: To evaluate the safety and efficacy of simultaneous angioplasty of vertebral and subclavian stenosis.

Material and methods: Fifteen patients (age 69.5 years, 46.7\% men, all symptomatic from posterior circulation (history of stroke, transient ischemic attack, chronic ischemia symptoms)) were scheduled for simultaneous SA/VA angioplasty. Clinical and duplex ultrasound follow-up was conducted 1, 6 and 12 months after the procedure.

Results: The technical success rate was 100\%. Single balloon-mounted stent angioplasty was performed for all VAs and for 13 (86.7\%) SAs. In 4 cases a simultaneous radial and femoral approach was required. The mean North American Symptomatic Carotid Endarterectomy Trial (NASCET) VA stenosis was reduced from $88.7 \pm 9.7 \%$ to $5.7 \pm 6.8 \%$ and SA stenosis from $80 \pm 12.2 \%$ to 11 $\pm 12.3 \%(p<0.01)$. No periprocedural death, stroke, myocardial infarction or transient ischemic attack occurred. During follow-up (range: 6-107 months) in 10 of 15 (66.7\%) patients relief of chronic ischemic symptoms was observed. No stroke/TIA occurred. One cardiovascular and 2 non-cardiovascular deaths were recorded. There was 1 symptomatic vertebral and 1 subclavian in-stent restenosis, and 2 cases of asymptomatic VA in-stent occlusion occurred.

Conclusions: Simultaneous vertebral and subclavian artery stenting is safe and effective. The restenosis rate remains at an acceptable level and it may be treated successfully with drug-eluting balloon angioplasty. In selected patients a dual radial and femoral approach may facilitate the procedure.
\end{abstract}

Key words: vertebral artery stenting, subclavian artery stenting, simultaneous angioplasty.

\section{Introduction}

The prevalence of subclavian artery (SA) stenosis in the general population is about $2 \%$ [1]. The real prevalence of extracranial vertebral artery (VA) stenosis generally is unknown, with estimates ranging from $7 \%$ to $40 \%$. Approximately one-quarter of ischemic strokes involve the vertebrobasilar circulation, and stenosis of the proximal VA may account for up to $20 \%$ of these events [2, 3].

In $98 \%$ of cases, VA arises from the proximal segment of the SA; however, coexisting stenosis of these arteries is uncommon. The majority of subclavian artery stenoses occur proximally to the origin of the VA, leading to VA flow reversal. Most patients remain asymptomatic due to contralateral VA supply increase. This phenomenon also plays a role in VA stenosis. Incidental SA stenosis in the absence of symptoms rarely requires revascularization treatment even if $3^{\text {rd }}$ degree VA flow reversal is present. However, in cases of inadequate collateral circulation supply or combination of vertebral and subclavian stenosis, typically symptoms occur mainly due to vertebrobasilar insufficiency $[4,5]$.

Surgical and endovascular approaches are available options of SA/VA stenosis treatment. However, it has been shown that endovascular intervention is much safer for this territory, and with advances in device technology, stent supported angioplasty has become the first line treatment $[5,6]$.

\section{Corresponding author:}

Damian R. Maciejewski MD, Department of Interventional Cardiology, Institute of Cardiology, Jagiellonian University Medical College, John Paul II Hospital, 80 Pradnicka St, 31-202 Krakow, Poland, phone: +48 609448 745, e-mail: damianmaciejewski@tlen.pl Received: 9.12.2016, accepted: 29.03.2017. 


\section{Aim}

The primary objective of this study is to evaluate the safety and efficacy of simultaneous subclavian and vertebral artery stenting.

\section{Material and methods}

Between February 2007 and July 2015 fifteen cases of patients with severe, symptomatic subclavian and vertebral artery stenosis were retrospectively extracted from the SA/VA angioplasty database in a single, high-volume center. The diagnosis of SA/VA stenosis was confirmed by Doppler ultrasound (DUS) and/or computed tomography angiography. Clinical symptoms, despite optimal medical therapy, were vertebrobasilar insufficiency (including vertigo, recurrent syncope) in all cases, prior posterior cerebrovascular incident in 5 (33.3\%) cases, upper extremity exertional ischemia in $9(60 \%)$ cases and subclavian-coronary steal syndrome in 1 (6.7\%) patient after coronary artery bypass grafting. In the group with prior stroke/TIA 4 patients presented vertigo and 1 recurrent syncope.

Table I shows detailed patient characteristics.

The qualification for simultaneous vertebral and subclavian artery angioplasty was performed on the basis of non-invasive examinations, neurological, cardiological and radiological consultation, and finally on direct angiography. Non-invasive diagnostics also includes ECG Holter monitoring to exclude significant arrhythmias, and transthoracic/transesophageal echocardiography to exclude cardiac origin embolization.

All patients received pretreatment with aspirin $(75 \mathrm{mg} /$ day) and a $300 \mathrm{mg}$ loading dose of clopidogrel before the procedure. After the angioplasty acetylsalicylic acid was maintained indefinitely, and $75 \mathrm{mg} /$ day of clopidogrel was continued for the following 3 months for bare metal stents and 12 months for drug-eluting stents.

The percutaneous arterial approach was obtained via the femoral artery in 11 (73.3\%) patients. A combined femoral and radial approach was required in 4 patients. The etiology of the obstructive lesions was atherosclerosis in all cases.

On the procedure day, the femoral artery was punctured and an $8 \mathrm{Fr}$ short arterial sheath was introduced. In cases with combined access a 6 Fr sheath in the ipsilateral radial artery was used. Before angioplasty a weight-adjusted dose of unfractionated heparin was administered. Over a 0.035 inch diagnostic wire, an 8 Fr guiding catheter was advanced toward the stenosis. Subclavian lesions were crossed using a 0.018 inch wire or steerable 0.035 inch hydrophilic coated wire. At the distal segment of the vertebral artery a 0.014 inch coronary guidewire was positioned. In a case of total occlusion, a lesion was successfully crossed from radial access with a 0.035 inch hydrophilic-coated guidewire.

The VA neuroprotection was not used as the system retrieval might be problematic in case of the VA ostium being covered by the SA stent. Direct stenting was performed when possible. Before and after the procedure the degree of stenosis was evaluated by quantitative angiography (Figures 1 A-D, 2 A-E).

The study participants were evaluated at 1, 6 and 12 months and then at yearly intervals after the procedure. Clinical/neurological examination, blood pressure measurement in both arms and ultrasonography were performed. In patients with significant restenosis confirmed by computed tomography (CT) angiography, re-angioplasty with drug-eluting ballon (DEB) was performed.

\section{Results}

Coexisting subclavian and vertebral artery stenosis was diagnoses in 15 out of 401 patients with SA stenosis and out of 459 patients with VA stenosis; all cases were left-side. Of those, one left subclavian occlusion with left vertebral stenosis was successfully treated by stenting (Figures $3 \mathrm{~A}-\mathrm{E}$ ). In all cases, subclavian artery stenting

Table I. Baseline clinical characteristics of patients $(N=15)$

\begin{tabular}{|c|c|}
\hline Parameter & Result \\
\hline Age [years] & $69.5 \pm 9.3$ \\
\hline Sex, male & $7(46.7 \%)$ \\
\hline Vertigo & $14(93.3 \%)$ \\
\hline Recurrent syncope & $2(13.3 \%)$ \\
\hline Prior stroke/TIA & $5(33.3 \%)$ \\
\hline TIA & $1(6.7 \%)$ \\
\hline Pontine stroke & $1(6.7 \%)$ \\
\hline Left sided cerebellar stroke & $2(13.3 \%)$ \\
\hline Occipital lobe stroke & $1(6.7 \%)$ \\
\hline Coronary subclavian steal & $1(6.7 \%)$ \\
\hline Arm claudication & $9(60 \%)$ \\
\hline Steal syndrome & $6(40 \%)$ \\
\hline Hypertension & 15 (100\%) \\
\hline Diabetes mellitus & $2(13.3 \%)$ \\
\hline Dyslipidemia & $15(100 \%)$ \\
\hline Coronary artery disease & $8(53.3 \%)$ \\
\hline Previous percutaneous coronary intervention & $5(33.3 \%)$ \\
\hline Previous myocardial infarction & $3(20 \%)$ \\
\hline History of coronary artery bypass grafting & $3(20 \%)$ \\
\hline Contralateral vertebral artery occlusion & $1(6.7 \%)$ \\
\hline Coexisting carotid artery stenosis & $6(40 \%)$ \\
\hline
\end{tabular}

TIA - transient ischemic attack. 

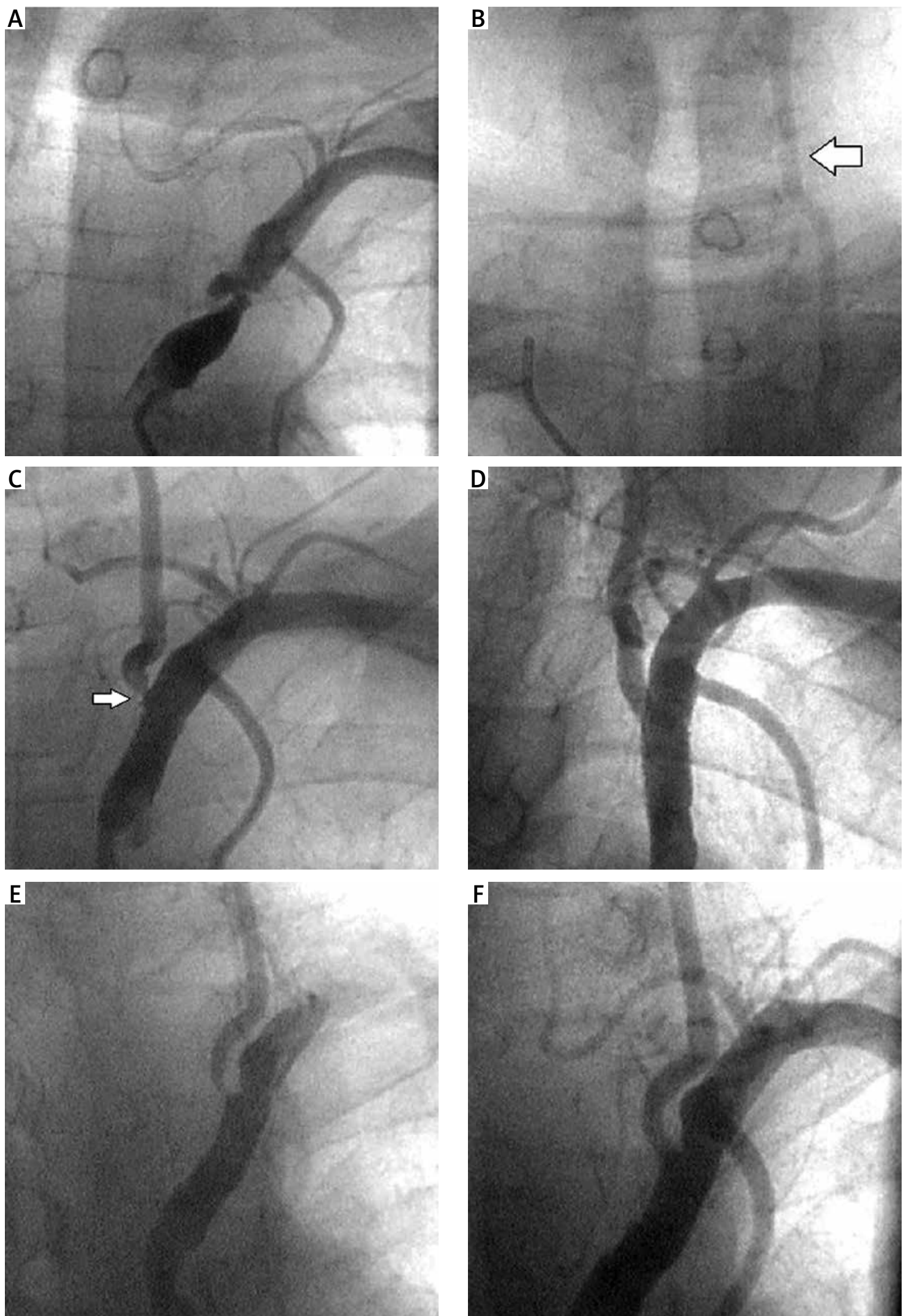

Figure 1. A - Selective angiography confirming left subclavian stenosis. B - Subclavian steal syndrome - flow reversal in the left vertebral artery (large arrow). C - Vertebral artery stenosis after subclavian stenting (small arrow). D - Final angiography showing optimal effect on VAS and SAS. E - Bare metal stent restenosis in the vertebral artery. F - Final effect after Dior $3.0 \times 15 \mathrm{~mm}$ drug-eluting balloon dilatation 

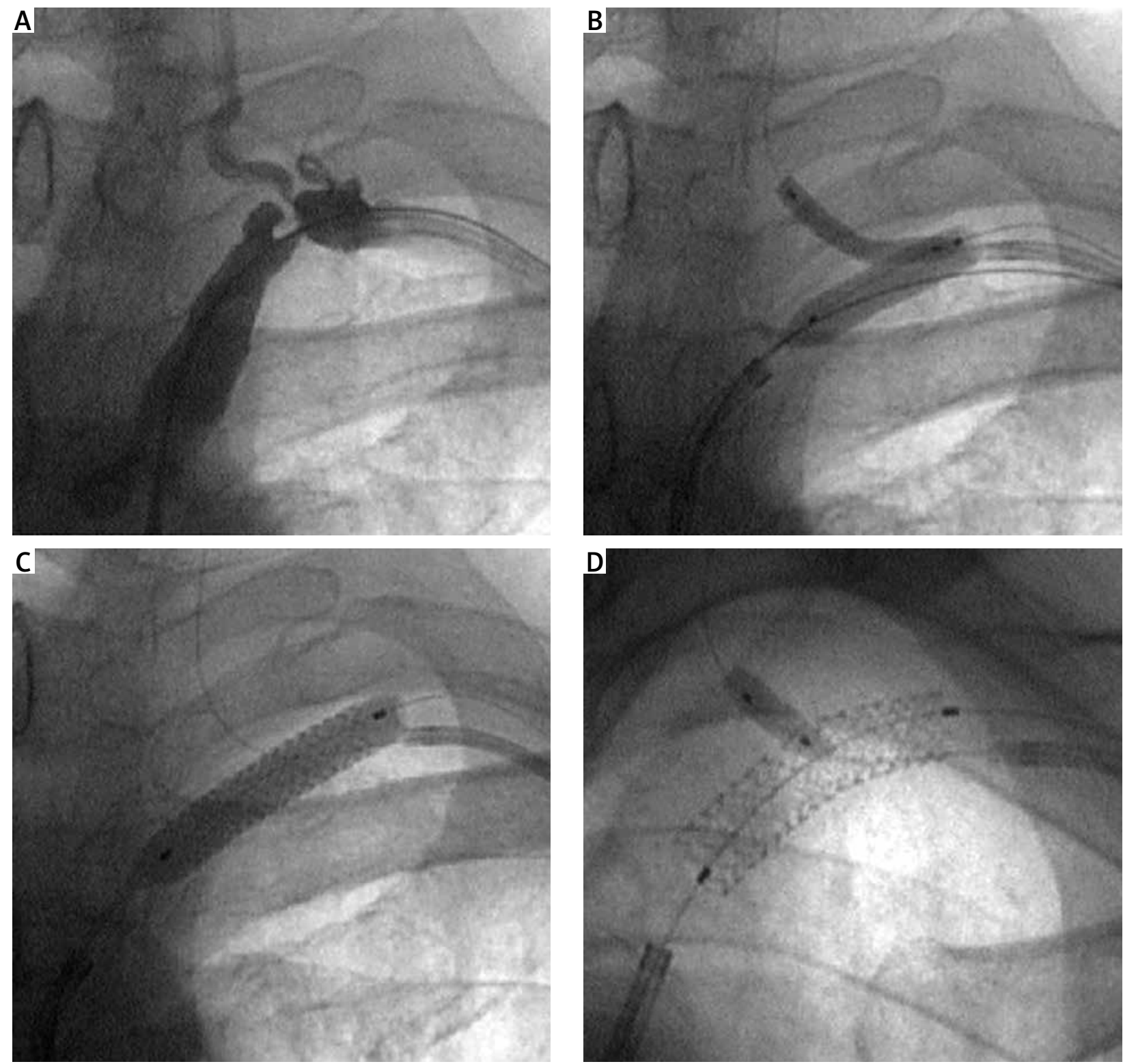

D
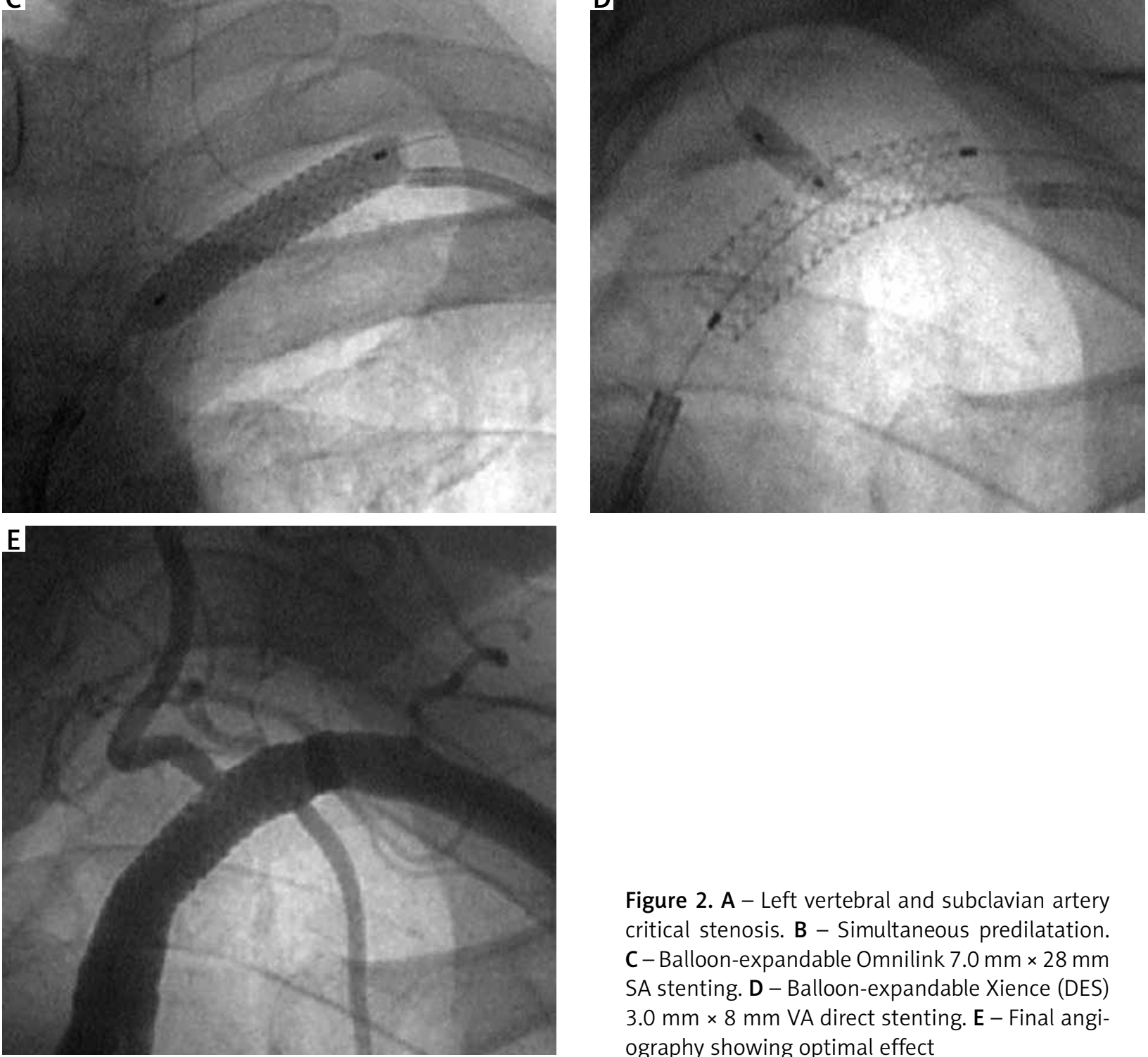

Figure 2. A - Left vertebral and subclavian artery critical stenosis. B - Simultaneous predilatation. C-Balloon-expandable Omnilink $7.0 \mathrm{~mm} \times 28 \mathrm{~mm}$ SA stenting. D - Balloon-expandable Xience (DES) $3.0 \mathrm{~mm} \times 8 \mathrm{~mm}$ VA direct stenting. E - Final angiography showing optimal effect 

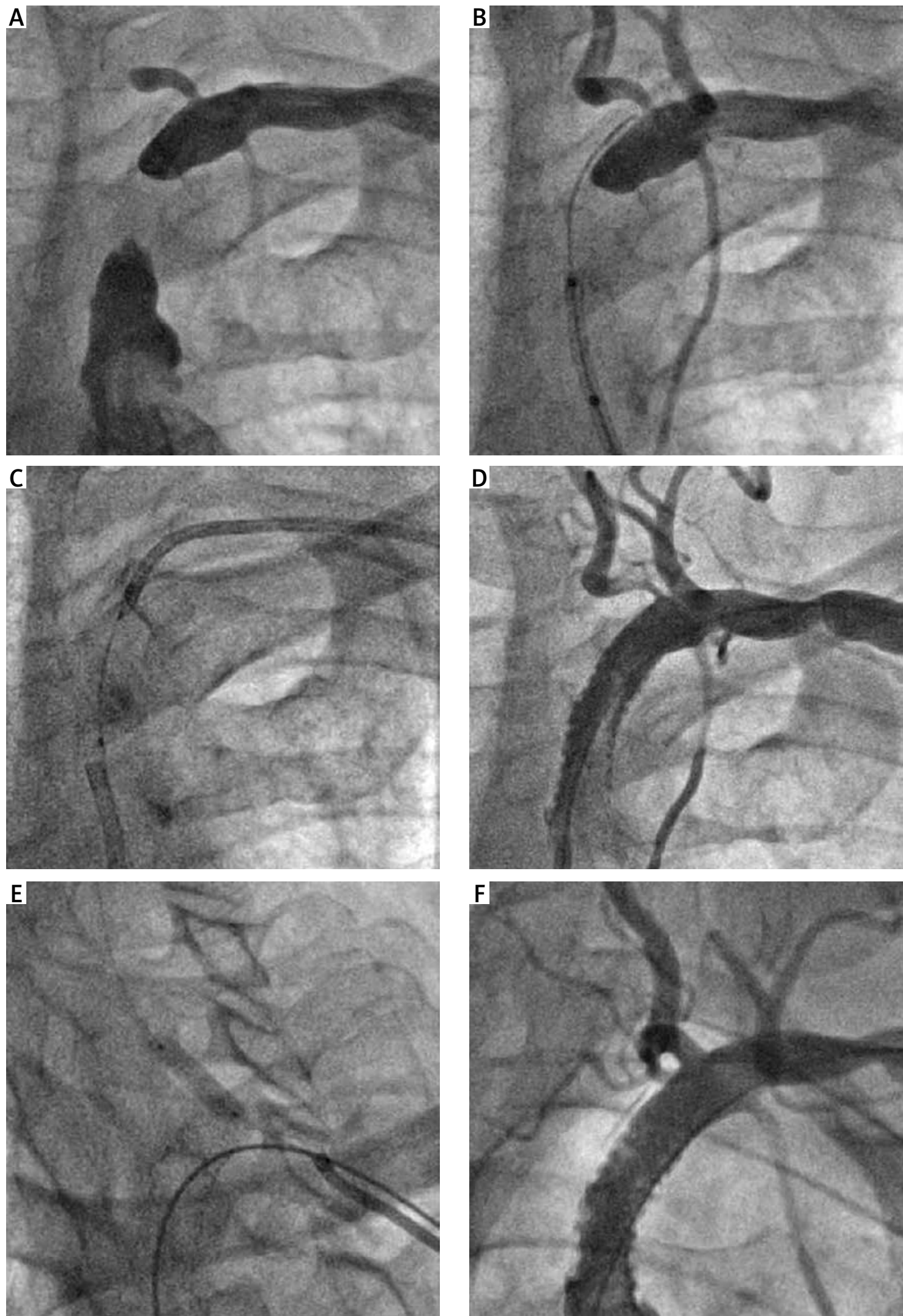

Figure 3. A - Selective angiography from combined approach. B - Unsuccessful attempt at crossing through occluded subclavian artery from femoral approach. C - Successful crossing via radial approach. D - After balloon-expandable Omnilink $9.0 \mathrm{~mm} \times 39 \mathrm{~mm}$ stent implantation. E - Balloon-expandable Omega (BMS) $4.0 \mathrm{~mm}$ $\times 12 \mathrm{~mm}$ VA direct stenting. $\mathbf{F}-$ Final angiography 
was the first procedure, and VA stent-supported angioplasty was performed after rewiring. In 2 of these 15 patients VA stenting was necessary due to severe plaque shift after subclavian artery stenting (SAS). Final kissing was performed with a non-compliant balloon in VA when needed. Technical success defined as stent implantation with residual stenosis $<20 \%$, no significant dissection and normal flow was achieved in all 15 (100\%) cases of vertebral and in 13 (86.7\%) cases of subclavian artery stenting. In 2 cases of SA self-expandable stent-supported angioplasty, the nominal stent diameter was not achieved due to increasing local pain during post-dilatation and the risk of artery perforation; thus $30 \%$ and $40 \%$ residual stenosis were measured. In all cases of VA angioplasty and in 12 cases of SA angioplasty single balloon-mounted stents were used. The mean North American Symptomatic Carotid Endarterectomy Trial (NASCET) VA stenosis was reduced from $88.7 \pm 9.7 \%$ to $5.7 \pm 6.8 \%$ and SA stenosis from $80 \pm 12.2 \%$ to $11 \pm 12.3 \%(p<0.01)$. The preprocedural discrepancy in systolic blood pressure between the upper extremities ranged from 15 to $57 \mathrm{~mm} \mathrm{Hg}$ with a mean of $32.5 \mathrm{~mm} \mathrm{Hg}$. The postprocedural differences ranged from 0 to $20 \mathrm{~mm} \mathrm{Hg}$ with a mean of $5.5 \mathrm{~mm} \mathrm{Hg}$ $(p<0.01)$. Procedural data are summarized in Table II.

No periprocedural death, stroke, myocardial infarction or transient ischemic attack occurred. In 11 patients with symptomatic coronary artery disease, coronary angiography was performed. Three of these patients underwent successful percutaneous coronary angioplasty 2-6 weeks after VA/SA stenting. During follow-up (range: 6-107 months) in 10 of 15 patients release of chronic ischemia symptoms was observed. No new posterior circulation stroke/transient ischemic attack (TIA) occurred. In 2 out of 3 patients with recurrent symptoms, critical restenosis was revealed - one in a VA stent (at 31 months of follow-up; Figure $1 \mathrm{E}$ ) and the second in an SA stent (13 months after the initial procedure). Both were successfully redilated with a drug-eluting balloon Freeway $7.0 \times 20 \mathrm{~mm}$ (Eurocor) and Dior $3.0 \times 15 \mathrm{~mm}$ (Eurocor) (Figure $1 \mathrm{~F})$. In 1 patient, borderline (50\%) left VA in-stent restenosis occurred 11 months after angioplasty and the patient was qualified for pharmacological treatment. In duplex ultrasound follow-up asymptomatic instent occlusion of the VA was revealed in 2 cases, the first after 5 months, the second 8 months after the procedure. During the follow-up 3 deaths were recorded, the first due to acute kidney failure (26 months follow-up), the second due to myocardial infarction (30 months follow-up) and the third due to liver cancer (49 months follow-up).

Periprocedural and follow-up Duplex ultrasound data are summarized in Table III.

\section{Discussion}

The majority of subclavian artery stenoses occur proximally to the ostium of the vertebral artery. The left sub- clavian artery is involved more often than the right. The proposed potential mechanism is that the acute angle of the origin of the left SA increases flow turbulence and accelerates atherosclerosis at the subclavian-aortic junction $[7,8]$. Despite VA flow reversal, only the minority of the patients become symptomatic. However, the risk of stroke and TIA recurrence in symptomatic patients may be three times higher compared with patients without stenosis [9]. The endovascular procedure, which is less invasive and shorter as compared to surgery, may be more beneficial, especially in patients with serious comorbidities $[6,10]$.

In our study all lesions were treated with stents as primary stenting has been shown to improve long-term

Table II. Procedural data

\begin{tabular}{|c|c|}
\hline Procedure & Result \\
\hline Left vertebral & $15(100 \%)$ \\
\hline Left subclavian & $15(100 \%)$ \\
\hline \multicolumn{2}{|l|}{ Vertebral: } \\
\hline Balloon-expandable bare-metal stent & $9(60 \%)$ \\
\hline Balloon-expandable drug-eluting stent & $6(40 \%)$ \\
\hline Stent diameter [mm] & $2.5-5.0$ \\
\hline Stent length $[\mathrm{mm}]$ & $8-14$ \\
\hline Direct stenting & $11(73.3 \%)$ \\
\hline \multicolumn{2}{|l|}{ Angiographic stenosis evaluation: } \\
\hline Pre-intervention & $88.7 \pm 9.7 \%$ \\
\hline Post-intervention & $5.7 \pm 6.8 \%$ \\
\hline \multicolumn{2}{|l|}{ Subclavian: } \\
\hline Occlusion & $1(6.7 \%)$ \\
\hline Balloon-expandable stent & $12(80 \%)$ \\
\hline Self-expandable stent & $3(20 \%)$ \\
\hline Stent diameter [mm] & $6-9$ \\
\hline Stent length $[\mathrm{mm}]$ & $17-39$ \\
\hline Direct stenting & $10(63.7 \%)$ \\
\hline \multicolumn{2}{|l|}{ Angiographic stenosis evaluation: } \\
\hline Pre-intervention & $80 \pm 12.2 \%$ \\
\hline Post-intervention & $11 \pm 12.3 \%$ \\
\hline \multicolumn{2}{|c|}{ Inter-arm systolic blood pressure difference [mm Hg]: } \\
\hline Pre-intervention, mean \pm SD & $32.5 \pm 13.5$ \\
\hline Post-intervention, mean \pm SD & $5.5 \pm 6.1$ \\
\hline \multicolumn{2}{|l|}{ Access: } \\
\hline Femoral & 11 (73.3\%) \\
\hline Combined & $4(26.7 \%)$ \\
\hline
\end{tabular}


Table III. Periprocedural and follow-up Duplex ultrasound data

\begin{tabular}{|c|c|c|c|c|c|c|c|c|}
\hline No. & SA stent & VA stent & $\begin{array}{c}\text { SA PSV } \\
\text { before } \\
\text { procedure } \\
{[\mathrm{m} / \mathrm{s}]}\end{array}$ & $\begin{array}{l}\text { Ostium VA PSV/ } \\
\text { EDV before } \\
\text { procedure }[\mathrm{m} / \mathrm{s}]\end{array}$ & $\begin{array}{c}\text { SA PSV after } \\
\text { procedure } \\
{[\mathrm{m} / \mathrm{s}]}\end{array}$ & $\begin{array}{l}\text { VA V2 PSV/ } \\
\text { EDV after } \\
\text { procedure } \\
{[\mathrm{m} / \mathrm{s}]} \\
\end{array}$ & $\begin{array}{c}\text { Follow-up } \\
\text { (5-65 months) } \\
\text { SA PSV } \\
{[\mathrm{m} / \mathrm{s}]}\end{array}$ & $\begin{array}{c}\text { Follow-up } \\
\text { (5-65 months) } \\
\text { VA V2 PSV/EDV } \\
{[\mathrm{m} / \mathrm{s}]}\end{array}$ \\
\hline 1 & $\begin{array}{l}\text { Omnilink }^{1} \\
6.0 / 18 \mathrm{~mm}\end{array}$ & $\begin{array}{l}\text { BMS Volo } \\
3.0 / 11 \mathrm{~mm}\end{array}$ & 6.5 & $4.2 / 1.1$ & 2.2 & $1.24 / 0.4$ & 3.0 & $0.4 / 0.2$ \\
\hline 2 & $\begin{array}{l}\text { Acculink }^{1} \\
7.0 / 30 \mathrm{~mm}\end{array}$ & $\begin{array}{l}\text { BMS Zeta }^{1} \\
3.0 / 13 \mathrm{~mm}\end{array}$ & 5.5 & $\begin{array}{c}\text { Flow reversal, } \\
\text { plaque shift }\end{array}$ & 1.2 & $0.46 / 0.12$ & 1.2 & $0.5 / 0.2$ \\
\hline 3 & $\begin{array}{l}\text { Express }^{2} \\
7.0 / 17 \mathrm{~mm}\end{array}$ & $\begin{array}{l}\text { BMS Skylor } \\
3.0 / 13 \mathrm{~mm}\end{array}$ & 4.0 & $\begin{array}{l}\text { Occlusion } \\
\text { suspected }\end{array}$ & 1.86 & $0.41 / 0.13$ & 1.4 & $0.39 / 0.09$ \\
\hline 4 & $\begin{array}{l}\text { Nefro }^{3} \\
7.0 / 18 \mathrm{~mm}\end{array}$ & $\begin{array}{l}\text { BMS Skylor }^{6} \\
3.5 / 10 \mathrm{~mm}\end{array}$ & Unknown & Flow reversal & 1.46 & $0.56 / 0.16$ & 2.2 & $\begin{array}{c}0.5 / 0.2- \\
\text { restenosis }\end{array}$ \\
\hline 5 & $\begin{array}{l}\text { Omnilink }^{1} \\
8.0 / 18 \mathrm{~mm}\end{array}$ & $\begin{array}{c}\text { BMS Chopin }^{3} \\
4.5 / 8 \mathrm{~mm}\end{array}$ & 5.5 & Unknown & 2.0 & $1.02 / 0.23$ & 2.2 & $0.85 / 0.19$ \\
\hline 6 & $\begin{array}{l}\text { Nefro }^{3} \\
7.0 / 16 \mathrm{~mm}\end{array}$ & $\begin{array}{c}\text { BMS Liberte }{ }^{2} \\
4.0 / 8 \mathrm{~mm}\end{array}$ & 5.75 & $4.5 / 0.9$ & 1.8 & $1.3 / 0.31$ & 1.8 & $\begin{array}{l}0.15 / 0.05- \\
\text { borderline } \\
\text { restenosis }\end{array}$ \\
\hline 7 & $\begin{array}{l}\text { Visi-Pro } \\
9.0 / 37 \mathrm{~mm}\end{array}$ & $\begin{array}{c}\text { BMS Gazelle }^{7} \\
4.0 / 8 \mathrm{~mm}\end{array}$ & 5.5 & Plaque shift & 3.5 & $1.02 / 0.21$ & 3.7 & $1.1 / 0.3$ \\
\hline 8 & $\begin{array}{l}\text { Absolute Pro }{ }^{1} \\
8.0 / 30 \mathrm{~mm}\end{array}$ & $\begin{array}{l}\text { BMS Vision }^{1} \\
4.0 / 8 \mathrm{~mm}\end{array}$ & 4.0 & $4.0 / 1.7$ & 1.8 & $0.45 / 0.11$ & 1.4 & $0.27 / 0.12$ \\
\hline 9 & $\begin{array}{l}\text { Omnilink }^{1} \\
9.0 / 39 \mathrm{~mm}\end{array}$ & $\begin{array}{c}\text { BMS Omega }^{2} \\
4.0 / 12 \mathrm{~mm}\end{array}$ & Occlusion & Flow reversal & 2.1 & $0.27 / 0.11$ & 2.0 & $\begin{array}{l}\text { Asymptomatic } \\
\text { occlusion }\end{array}$ \\
\hline 10 & $\begin{array}{l}\text { Omnilink }{ }^{1} \\
9.0 / 39 \mathrm{~mm}\end{array}$ & $\begin{array}{l}\text { DES Nefro }{ }^{3} \\
5.0 / 8 \mathrm{~mm}\end{array}$ & 4.6 & $\begin{array}{l}\text { Occlusion } \\
\text { suspected }\end{array}$ & 2.1 & $0.38 / 0.11$ & 2.5 & $0.4 / 0.1$ \\
\hline 11 & $\begin{array}{l}\text { RX Herculink } \\
\text { Elite }^{1} \\
6.5 / 18 \mathrm{~mm}\end{array}$ & $\begin{array}{c}\text { DES Endeavor } \\
\text { Resolute } \mathrm{RX}^{8} \\
2.5 / 14 \mathrm{~mm}\end{array}$ & Unknown & Flow reversal & 2.7 & $0.61 / 0.15$ & 2.0 & $\begin{array}{l}\text { Asymptomatic } \\
\text { occlusion }\end{array}$ \\
\hline 12 & $\begin{array}{l}\text { Zilver }^{5} \\
8.0 / 30 \mathrm{~mm}\end{array}$ & $\begin{array}{c}\text { DES Endeavor }{ }^{8} \\
3.5 / 12 \mathrm{~mm}\end{array}$ & 4.5 & Flow reversal & 2.0 & $0.56 / 0.2$ & $\begin{array}{c}4.5- \\
\text { restenosis }\end{array}$ & $0.25 / 0.08$ \\
\hline 13 & $\begin{array}{l}\text { Omnilink }{ }^{1} \\
\text { 7.0/28 mm }\end{array}$ & $\begin{array}{l}\text { DES XienceV }{ }^{1} \\
3.0 / 8 \mathrm{~mm}\end{array}$ & 8.6 & Flow reversal & 2.8 & $0.54 / 0.12$ & 3.2 & $0.15 / 0.05$ \\
\hline 14 & $\begin{array}{l}\text { Neptun }^{3} \\
7.0 / 20 \mathrm{~mm}\end{array}$ & $\begin{array}{c}\text { DES Biomatrix }^{7} \\
4.0 / 8 \mathrm{~mm}\end{array}$ & $\begin{array}{l}\text { CT angiog- } \\
\text { raphy }\end{array}$ & CT angiography & 2.2 & $0.7 / 0.2$ & 2.7 & $0.76 / 0.25$ \\
\hline 15 & $\begin{array}{l}\text { Omnilink Elite }{ }^{1} \\
\text { 7.0/19 mm }\end{array}$ & $\begin{array}{l}\text { DES Resolute } \\
\text { Integrity }^{8} \\
2.75 / 14 \mathrm{~mm}\end{array}$ & $\begin{array}{l}\text { CT angiog- } \\
\text { raphy }\end{array}$ & CT angiography & 1.6 & $0.45 / 0.12$ & 2.4 & $0.3 / 0.1$ \\
\hline
\end{tabular}

*Velocity measurements were made at $60^{\circ}$ insonation angle. PSV/EDV - peak systolic velocity/end-diastolic velocity, SA - subclavian artery, VA V2 - V2 segment of vertebral artery, BMS - bare metal stent, DES - drug-eluting stent. ${ }^{7} \mathrm{Abbott},{ }^{2}$ Boston Scientific, ${ }^{3}$ Balton, ${ }^{4} \mathrm{ev} 3,{ }^{5} \mathrm{Cook}$ Medical, ${ }^{6}$ Invatec, ${ }^{7}$ Biosensors, ${ }^{8} \mathrm{Medtronic}$.

patency compared with balloon procedures alone [11, 12]. Despite higher rates of restenosis as compared to other treatment options, balloon angioplasty may be considered in patients who are unable to tolerate open surgery and/or with contraindications to dual-antiplatelet therapy.

In subclavian artery angioplasty, we preferred balloon-expandable stents, especially for ostial lesions. They offer higher radial force and more precise deployment, which allows one to avoid incidental coverage the origin of the vertebral or internal mammary artery. On the other hand, self-expanding stents are easier to deliver through a tortuous lesion.

It is well known that small caliber arteries are more prone to restenosis as compared to larger arteries. The use of drug-eluting stents (DES) in these arteries might be of benefit [13-15]. In our study 6 DES were used in the vertebral lesions with 1 in-stent occlusion. There was 1 case of restenosis and 1 case of occlusion in bare-metal stents (Table III).

Simultaneous vertebral and subclavian artery stenting is a technically demanding endovascular procedure which should be performed in high-volume centers. In some cases wiring of the vertebral artery may be challenging due to tortuosity of the vessel and multiple views may be required to adequately visualize the VA ostium. For this reason a radial approach may be beneficial especially when proximal SA stenosis displaces the wire away from the artery ostium (Figure 2 A) [16].

Vertebrobasilar ischemia may be provoked both by vertebral and subclavian artery stenosis. Therefore simultaneous artery stenting seems to be the optimal solution. There is also no need for subsequent hospitalization for a second procedure, which decreases the risk of possi- 
ble access complications and reduces costs. On the other hand, the larger amount of contrast medium used during the procedure requires optimal patient hydration and kidney function evaluation.

\section{Conclusions}

Simultaneous vertebral and subclavian stenting is a safe and effective procedure with regard to the initial success rate and long-term patency. Despite severe limitations due to retrospective analysis and a small cohort of 15 patients, the restenosis and occlusion rate remained at an acceptable level and, if possible, it may be treated successfully with drug-eluting balloon angioplasty. In selected patients a dual radial and femoral approach may facilitate the procedure.

\section{Conflict of interest}

The authors declare no conflict of interest.

\section{References}

1. Burihan E, Soma F, lared W. Angioplasty versus stenting for subclavian artery stenosis. The Cochrane database of systematic reviews. 2011; 10: CD008461.

2. Bogousslavsky J, Van Melle G, Regli F. The Lausanne Stroke Registry: analysis of 1,000 consecutive patients with first stroke. Stroke 1988; 19: 1083-92.

3. Compter A, van der Worp HB, Algra A, et al. Prevalence and prognosis of asymptomatic vertebral artery origin stenosis in patients with clinically manifest arterial disease. Stroke 2011; 42: 2795-800.

4. Wrotniak L, Kablak-Ziembicka A, Roslawiecka A, et al. Resolution of ischemic symptoms after percutaneous angioplasty for asymptomatic subclavian artery stenosis. J Vasc Surg 2016; 64: 684-91.

5. Potter BJ, Pinto DS. Subclavian steal syndrome. Circulation 2014; 129: 2320-3.

6. Higashimori A, Morioka N, Shiotani S, et al. Long-term results of primary stenting for subclavian artery disease. Catheter Cardiovasc Interv 2013; 82: 696-700.

7. Nicholls SC, Koutlas TC, Strandness DE. Clinical significance of retrograde flow in the vertebral artery. Ann Vasc Surg 1991; 5: 331-6.

8. Labropoulos N, Nandivada P, Bekelis K. Prevalence and impact of the subclavian steal syndrome. Ann Surg 2010; 252: 166-70.

9. Gulli G, Marquardt L, Rothwell PM, et al. Stroke risk after posterior circulation stroke/transient ischemic attack and its relationship to site of vertebrobasilar stenosis: pooled data analysis from prospective studies. Stroke 2013; 44: 598-604.

10. Eberhardt O, Naegele T, Raygrotzki S, et al. Stenting of vertebrobasilar arteries in symptomatic atherosclerotic disease and acute occlusion: case series and review of the literature. J Vasc Surg 2006; 43: 1145-54.

11. Cloud GC, Crawley F, Clifton A, et al. Vertebral artery origin angioplasty and primary stenting: safety and restenosis rates in a prospective series. J Neurol Neurosurg Psychiatry 2003; 74 : 586-90.

12. Mohammadian R, Sharifipour E, Mansourizadeh R, et al. Angioplasty and stenting of symptomatic vertebral artery stenosis.
Clinical and angiographic follow-up of 206 cases from northwest Iran. Neuroradiol J 2013; 26: 454-63.

13. Tank VH, Ghosh R, Gupta V, et al. Drug eluting stents versus bare metal stents for the treatment of extracranial vertebral artery disease: a meta-analysis. J Neurointerv Surg 2016; 8: 770-4.

14. Paluszek P, Pieniążek P, Musiałek P, et al. Symptomatic vertebral artery stenting with use of bare metal and drug elitings stents. Postep Kardiol Inter 2009; 5: 1-6.

15. Langwieser N, Buyer D, Schuster T, et al. Bare metal vs. drug-eluting stents for extracranial vertebral artery disease: a meta-analysis of nonrandomized comparative studies. J Endovasc Ther 2014; 21: 683-92.

16. Maciejewski D, Tekieli $Ł$, Kabłak-Ziembicka A, et al. Transradial approach for vertebral artery stenting. Postep Kardiol Inter 2015; 11: 32-6. 